\title{
INCORPORATION OF LNG INTO SMALL GAS NETWORKS VIA FSRUs
}

\author{
DEVASANTHINI DEVARAJ ${ }^{1,2}$, PHILIP DONNELLAN ${ }^{1} \&$ EOIN SYRON $^{1,2}$ \\ ${ }^{1}$ School of Chemical \& Bioprocess Engineering, University College Dublin, Ireland. \\ ${ }^{2}$ UCD Energy Institute, University College Dublin, Ireland.
}

\begin{abstract}
Geopolitical risks on pipeline gas imports, increasing natural gas demand and the need to ensure continuous power supply with ever increasing fluctuating renewable power generation require diversification of gas sources to ensure supply security. With the global liquefied natural gas (LNG) trade increasing every year and natural gas prices remaining relatively low, more and more countries are interested in investing in regasification infrastructure. Establishing a floating storage and regasification unit (FSRU) and importing LNG has several advantages: lower cost compared to an onshore terminal, flexibility in relocation and the availability of short-term contracts all of which help serve small markets. FSRUs can also be operated in standby mode or used as an LNG storage facility. Operating an FSRU as a storage facility while beneficial for small networks introduces the challenges of LNG weathering and managing of the boil-off gas (BOG). To investigate these challenges on operation, a mathematical model is developed to determine the boil-off rate (BOR) over various time frames. The initial BOR is $0.129 \%$ of the initial storage volume increased to $0.143 \%$ after 10 weeks. Subsequent use of Aspen HYSYS to determine the change in LNG composition determined that Wobbe Index (WI) of the LNG varied from 51.58 to $51.616 \mathrm{MJ} / \mathrm{Nm}^{3}$ after 10 weeks of storage. An annual economic estimation of operating FSRU as a storage facility was carried out determining that the per unit price of gas obtained from regasified LNG is at least $42 \%$ lower than the current per unit price of gas in Ireland.
\end{abstract}

Keywords: Boil-off Rate, FSRU, LNG Storage, LNG Weathering.

\section{INTRODUCTION}

After steady growth in recent years, global liquefied natural gas (LNG) trade reached a record 293.1 million tonnes (MT) in 2018 which is a 12\% increase from 2016 [1]. This is due to increased LNG supply by Australian and US projects, which added new liquefaction trains at Australia Pacific LNG and at Sabine Pass LNG. China, India and Egypt are the major importers of LNG. With a significant amount of new supply available, LNG producers are looking outside established markets to develop new demand. According to the international gas union (IGU) [1], the increased LNG supply may result in additional deliveries to European markets with ample natural gas infrastructure, such as the United Kingdom, France and Spain. IGU believe that although the markets are notionally small, these emerging demand outlets could amount to substantial volumes in aggregate. Increasing customer requests for short-term gas purchase contracts led to the development of floating storage and regasification unit (FSRU). The global floating regasification capacity in 2018 was 84 MT per annum. It is a $9.1 \%$ increase from 2016 [2] and 55\% increase from 2014 [3]. FSRUs serve as an excellent opportunity to help in expanding the LNG market internationally.

FSRUs use the same technology as onshore LNG terminals. The difference is that the equipment is marinized to be suitable for shipyard construction and marine operation. For a newly built FSRU, the equipment is normally integrated into the vessel and constructed with the ship. The process components are incorporated into the FSRU resulting in lower CAPEX. Also, low contingency and the low owner charges for the FSRU make the overall investment lower. Constructing a new FSRU can cost 50-60\% of an onshore terminal and can be delivered in half the time [4]. LNG tankers can also be converted into FSRUs. For the conversion of 
LNG tanker to FSRU, the equipment is normally built as a separate module or modules and retrofitted to the tanker in a shipyard to minimize time.

The FSRUs have a capacity of 130,000-170,000 $\mathrm{Nm}^{3}$. They are equipped with storage tanks, which are membrane or moss-type tanks and vaporizers. FSRUs are loaded with LNG from tankers. LNG is regasified in the vaporizer unit and injected into the gas network or used for power generation. Some FSRUs provide boil-off gas (BOG) management using recondensers [4]. FSRUs can be operated in several modes. They can be permanently moored offshore, and full regasification occurs following an LNG delivery. They can be operated in stand-by mode. In this scenario, the regasification units continuously run on a minimum gas send-out rate which can be ramped up to required send-out rate on demand (e.g. FSRU Toscana in Italy). FSRUs can also be used as an LNG storage facility owing to their huge capacity. Lower cost, commercial flexibility and reusable asset feature of FSRUs are the significant reasons for their rapid growth.

The main challenges associated with LNG storage are the BOG management and LNG weathering. Due to heat entering the tank during the storage period, a fraction of the LNG is continuously evaporated producing BOG. This results in a continuous loss of LNG. In general, the boil-off rate (BOR) is $0.15 \%$ per day [5]. The BOG can be injected into the gas network or re-liquefied and returned as LNG to the storage tanks. Also, the heat ingress into the storage tanks causes the most volatile compounds in LNG, namely nitrogen and methane to evaporate more than the heavier compounds. This gradually changes the composition of the LNG and alters the Wobbe index (WI) of the LNG. This process is called aging or LNG weathering. The altered WI value is usually higher than the original WI of the LNG. It is essential to ensure that the altered WI remains within the operational limits of the network because all gas-fired equipment are designed to operate within a range of gas specifications [6] which are presented in Table 1.

Ireland is considered for a case study. The natural gas network in Ireland comprises 14,172 $\mathrm{km}$ of transmission and distribution pipelines [7]. It is relatively a smaller network compared to gas networks in countries like France and Germany. It is half the size of the French network and $1 / 38$ th of the size of the German network. There are three entry points to the Irish gas network. The Corrib and Inch gas production fields contribute to $49 \%$ and $4 \%$ of the total gas supply, respectively. The balance is supplied via imports from the UK [7]. The interconnector at Moffat in the UK supplying gas is currently physically unidirectional.

Natural gas plays an important role in decarbonizing energy systems and it acts as a transition fuel helping economies to achieve short-term carbon emission targets [8], especially

Table 1: Summary of UK gas safety (Management)

regulation, 1995.a.

\begin{tabular}{lc}
\hline Components & Permissible limits \\
\hline WI MJ $/ \mathrm{m}^{3}$ & $47.2-51.41[4.65-52.85]$ \\
Hydrogen Sulphide $\mathrm{mg} / \mathrm{m}^{3}$ & $<5$ \\
Total Sulphur $\mathrm{mg} / \mathrm{m}^{3}$ & $<50$ \\
Oxygen $(\mathrm{mol} \%)$ & $<0.2$ \\
Hydrogen $(\mathrm{mol} \%)$ & $<0.1$ \\
Sooting Index & $<0.60$ \\
Incomplete combustion Factor & $<0.48[<1.49]$ \\
\hline
\end{tabular}


when these economies switch from coal-fired to gas-fired power plant. In Ireland, almost $60 \%$ of the power generation comes from natural gas but the largest power station, Moneypoint (915 MW) which supplies the base load is coal-fired. Switching Moneypoint to natural gas will result in a decrease of $539 \mathrm{gCO}_{2} \mathrm{e} / \mathrm{kWh}$ [8]. According to Sustainable Energy Authority of Ireland (SEAI), the natural gas consumption in Ireland is $4.73 \mathrm{Bcm}$ in 2018 and it is expected to increase up to $6 \mathrm{Bcm}$ in the year 2022 [9]. It is anticipated that the supply of Corrib gas field would decline after 2020. This will force Ireland to rely heavily on imports from the UK in the future and the uncertainty of UK to remain as a member of the Integrated Single Energy Market post Brexit is a risk factor. The UK may face tariffs for energy trade and Ireland will subsequently face higher gas consumption prices.

Incorporating LNG into gas network and storage of LNG could be favorable with respect to the diversification of gas sources and to ensure supply security. All load demand conditions must be met by grid operations regardless of the availability of renewable power. Reserve capacity and ramping capacities must be constantly available due to the rapidity at which the intermittent sources come online or dropout [8]. Hence, high penetration of renewable energy requires co-deployment of controllable generators or energy storage to achieve system-level dynamics. FSRUs can be operated as LNG storage facilities as they have several advantages. Recent FSRUs have a total capacity of $170,000 \mathrm{Nm}^{3}$ and gas sent out rate of $17 \mathrm{Mm}^{3}$ per day [4]. A single FSRU is capable of supplying Ireland's daily gas demand (average demand was 13.43 $\mathrm{Mm}^{3}$ and average winter demand was $15.38 \mathrm{Mm}^{3}$ in 2017/18) [10]. They require a lower investment than onshore LNG terminal and can be leased on short-term contracts. The built-in vaporizer unit enables FSRUs to be operated in various level of regasification. They can be relocated. As the LNG is aimed to reach market overseas, the LNG producers usually develop an annual delivery schedule for each of their customers. Operating FSRU as a storage unit can overcome the rigid LNG delivery schedule.

A mathematical model is developed in reference to Calogero et al. [11] to determine the BOR for storage tank. This metric is a representation of the amount of LNG that is lost during the storage period and is expressed in $\%$ of total liquid volume per unit time. Simulation of the storage tank is performed in Aspen HYSYS to determine the change in LNG composition. The steps involved in model development are detailed in Section 2.

To determine the economic feasibility, the production cost to establish the FSRU as a storage facility is estimated. The LNG purchase cost used is 6.11 dollars per one million British Thermal Units (\$/MMBtu) [1]. It is the average spot price at the UK National Balancing Point in 2018. Considering that Sabine Pass in the United States was the most active LNG export terminal in 2018, the transport cost estimate is obtained for the distance between the United States and Ireland and it is $0.0536 \mathrm{MM} \$$ /day. FSRU leasing charge follows an overall tolling rate, where the payment made is based on the amount of LNG regasified. It is also dependent on the terminal utilization factor, and the rate is usually 0.55\$/MMBtu [4]. The regasification cost is determined for the cargo available at a specific time and the rate is $0.35 \$$ MMBtu. LNG lost as BOG does not account for the regasification cost. Four scenarios are created to identify the feasible option and the results of economic estimate are discussed in Section 3.

- LNG storage for up to 5 weeks in 1 FSRU.

- LNG storage for up to 5 weeks in 2 FSRUs.

- LNG storage for up to 10 weeks in 1 FSRU.

- LNG storage for up to 10 weeks in 2 FSRUs. 


\section{METHODOLOGY}

The overall heat transfer coefficient, $U$, is determined based on the wall structure of FSRU tank. The capacity of the tank is considered to be $170,000 \mathrm{~m}^{3}$. The walls comprise two layers of membranes and insulation (primary and secondary) separated by water ballast tank. The other dimensions of the FSRU used in this calculation are presented in Table 2 [5].

$$
\frac{1}{U_{j}}=\frac{1}{h_{0}}+\frac{A_{0}}{A_{i} h_{i j}}+\sum_{l=1}^{3} \frac{A_{0}}{A_{m l}} \frac{e_{l}}{\lambda_{l}}
$$

where subscript $j$ refers to wet or dry part of the inside wall, $h$ is the convection heat transfer coefficient, $A$ is the area of the storage tank, subscripts $i$ and $o$ refer to internal and external, respectively, $A_{m}$ is the mean heat transfer area, $e$ is equivalent insulation thickness and $\lambda$ is the thermal conductivity of layer material.

The heat ingress, $Q$, into the tank is determined followed by the calculation of latent heat of vaporization [12].

$$
\begin{gathered}
Q=\left(U_{\text {wet }} A_{w e t}+U_{d r y} A_{d r y}\right) \cdot\left(T_{a i r}-T\right) \\
\Delta h_{\text {vap }_{L N G}}=\sum_{i=1}^{n} X_{L N G_{i}} * \Delta h_{\text {vap }_{i}}
\end{gathered}
$$

where,

$$
\Delta h_{v a p_{i}}=A_{i} *\left(X_{i}^{t}\right)^{m}+B_{i} *\left(X_{i}^{t}\right)^{1+m}+C_{i} *\left(X_{i}^{t}\right)^{2+m}+D_{i} *\left(X_{i}^{t}\right)^{3+m}
$$

$A, B, C, D$ and $m$ are substance-dependent parameters and $X_{i}$ is calculated based on the critical temperature of the individual components. The rate at which the BOG is produced on a daily basis is determined using the following expression [13]:

$$
B O R=\frac{V_{B O G} * 24}{V_{L N G} * 24}=\frac{Q * 3600 * 24}{\Delta H^{*} V_{L N G} * \rho} * 100
$$

Table 2: Tank specifications of FSRU vessel.

\begin{tabular}{lcc}
\hline Tank Specifications & Exterior & Interior \\
\hline Length (m) & 295 & 292.468 \\
Beam (m) & 50 & 47.468 \\
Depth (m) & 27 & 24.468 \\
\hline \multicolumn{2}{c}{ Other specifications } \\
\hline Primary membrane thickness (mm) & 1.2 \\
Secondary membrane thickness (mm) & 1.2 \\
Primary insulation thickness (mm) & 300 \\
Secondary insulation thickness (mm) & 230 \\
Width of water ballast tank (m) & 2 \\
\hline
\end{tabular}


Table 3: Composition of the LNG.

\begin{tabular}{ccccccc}
\hline Components & Methane & Ethane & Propane & i-Butane & n-Butane & Nitrogen \\
\hline mol $(\%)$ & 0.9307 & 0.0661 & 0.0006 & 0.0000 & 0.0000 & 0.0026 \\
\hline
\end{tabular}

where $V_{\mathrm{BOG}}$ and $V_{\mathrm{LNG}}$ are the volumes of BOG and LNG, respectively, $Q$ is the heat ingress from eqn (2) and $\Delta H$ is the latent heat of vaporization from eqn (3) and $\rho$ is the density of LNG. After the initial loss in the volume of LNG, the area exposed to heat varies. This alters the amount of heat ingress into the tank. The new $Q$ entering the system is calculated. This procedure is repeated for the desired period of time to obtain the trend for the BOR.

The Aspen HYSYS simulation of the storage tank is performed. The initial LNG composition considered for the simulation is presented in Table 3. Throughout the storage period, the mole fraction of the components of the LNG is obtained on a weekly basis. They are used in the calculation of heating values and WI of the LNG. This WI value is used to verify whether it is compliant with the operational limits of the network. The expression used to determine WI is given below.

$$
\text { WobbeIndex }=\frac{\text { Higher Heating Value }}{\sqrt{\text { Specific Gravity }}}
$$

Following the simulation, production cost and per unit price are calculated. Annual Production Cost $=$ LNG Purchase Cost + Transport Cost + FSRU Leasing Charge + Yearly Infrastructure Payment + Regasification Cost.

\section{RESULTS AND DISCUSSIONS}

The results of this study highlight two important observations in operating FSRU as a storage facility, the loss in LNG due to boil-off and change in WI on a weekly basis (represented in Fig. 1). BOR on day 1 is $0.129 \%$ of total LNG volume per day (calculated using eqn 5). It can be seen that the BOR increased throughout the storage period. After 10 weeks of storage,

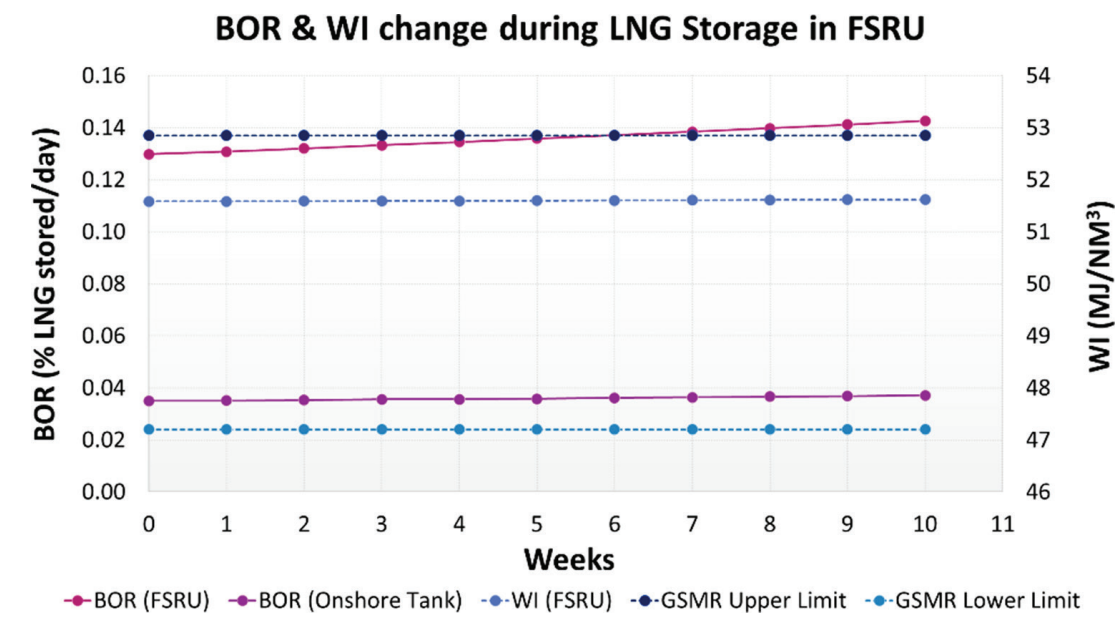

Figure 1: BOR and WI change during LNG storage in FSRU. 
LNG lost is $15,214 \mathrm{~m}^{3}$. The initial WI is $51.58 \mathrm{MJ} / \mathrm{Nm}^{3}$. Due to weathering, WI continuously increases during storage. The WI after 10 weeks is $0.07 \%$ higher than the initial value and is ensured that it is compliant with the network specifications for WI.

The loss of LNG is a continuous phenomenon and the volume of LNG available in the storage tank at specific time period is represented in Fig. 2.

Aspen simulations are also performed for three different LNG compositions (light LNG, Heavy LNG and LNG with $5 \% \mathrm{~N}_{2}$ ) to determine the WI values for specific intervals over the storage period (Fig. 3). The WI values of all types of LNG after 10 weeks of storage are found to be higher than the initial WI. It is ensured that all types of LNG are compliant with the network limitations for WI. Figure 3 also represents change in WI values for the BOG generated from the respective LNGs. These values are required if they are to be injected into the network. BOG from light and heavy LNG is suitable for network injection from day 1.

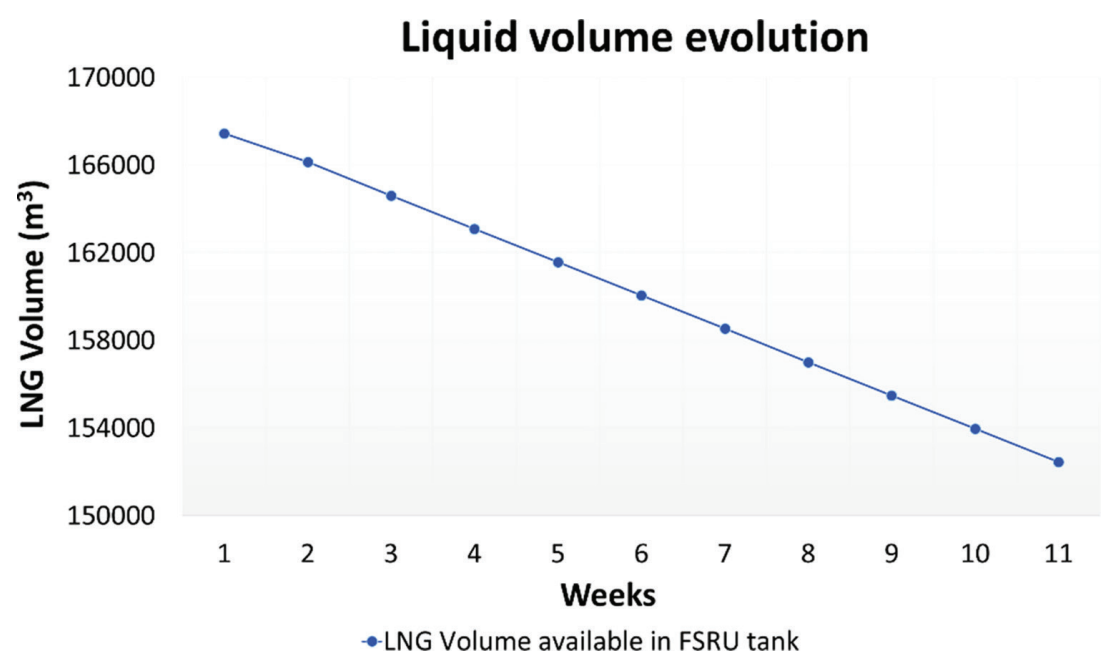

Figure 2: Liquid volume evolution.

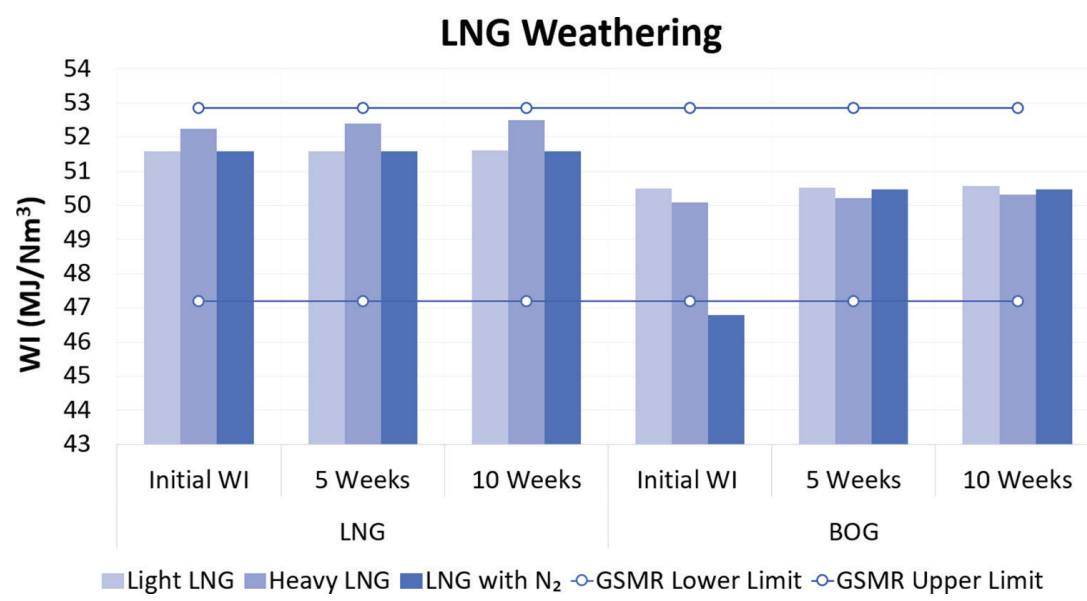

Figure 3: Representation of LNG Weathering during storage in FSRU. 
However, initial WI of BOG from 'LNG with $\mathrm{N}_{2}$ ' is found to be low $\left(46.79 \mathrm{MJ} / \mathrm{Nm}^{3}\right)$ and is not suitable for network injection. This is because the BOG is composed of nitrogen and methane resulting in a lower heating value yielding a lower WI. In this scenario, a small amount of LNG is regasified and blended with BOG. This is called forced boil-off. The composition of the forced BOG is the same as the LNG in the tank and is suitable for network injection. The forced boil-off is stopped after 4 hours, as the BOG itself becomes compliant with the network limits $\left(47.32 \mathrm{MJ} / \mathrm{Nm}^{3}\right)$. This is due to the decrease in nitrogen content in BOG.

Additional observations are made on the scenario where the regasification unit is operated continuously on a daily basis to supply the Irish network. The send-out rate of FSRU on full capacity is $17 \mathrm{Mm}^{3}$ per day. It will be able to serve as a reliable gas source to meet the daily demand of Ireland (average demand is $13.43 \mathrm{Mm}^{3}$ and average winter demand is $15.38 \mathrm{Mm}^{3}$ in 2017/18). Another option is to operate FSRU at a reduced send-out rate where it can serve as a substitute for pipeline imports. If the regasification unit is operated in $37 \%$ capacity, the FSRU can supply $47 \%$ of the gas demand (a substitute for imports from the UK). The excess supply from FSRU can also be potentially used for gas exports via Moffat, UK (undergoing development to be established as a reverse flow interconnector) [14].

Figure 4 is a graphical representation of the cost estimate, the annual production cost and per unit price. The step-wise calculation of the per unit price is presented in Table 4 .

- LNG storage in 1 FSRU-The difference in annual production cost between 5 and 10 weeks of storage is only $4.28 \%$ (despite the $50 \%$ reduction in purchase cost and transport cost). This is because the FSRU leasing charge and the tariff to access the Irish gas infrastructure constitutes the majority of the annual production cost.

- LNG Storage in 2 FSRUs-The difference in annual production cost between 5 weeks and 10 weeks of storage is only $5.99 \%$.

The lowest per unit price, 0.905 cent $/ \mathrm{kWh}$, is yielded by the scenario where two FSRU units store LNG for five weeks. This is due to increased gas supply and the same annual infrastructure payment despite having more than one FSRUs. The highest per unit price,
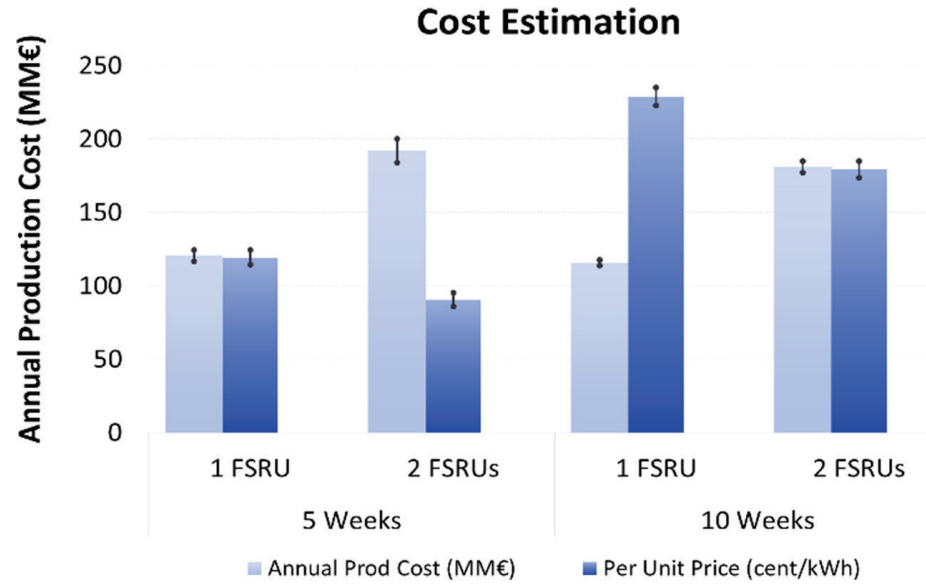

Figure 4: Cost estimate for establishment of FSRU as a storage facility. 
Table 4: Cost estimation for the four scenarios.

\begin{tabular}{lccccc}
\hline & & \multicolumn{4}{c}{ Cost Estimate } \\
& & & & 5 weeks & 10 Weeks \\
Cost Category & Units & 5 Weeks & 10 Weeks & (2 FSRUs) & (2 FSRUs) \\
\hline Purchase cost & $€ m m / y r$ & 0.30 & 0.15 & 0.63 & 0.30 \\
Regasification cost & $€ m m / y r$ & 0.02 & 0.01 & 0.03 & 0.02 \\
Transport cost & $€ m m / y r$ & 9.55 & 4.78 & 20.06 & 9.55 \\
Infrastructure Payment & $€ m m / y r$ & 50.00 & 50.00 & 50.00 & 50.00 \\
FSRU leasing charge & $€ m m / y r$ & 60.60 & 60.60 & 121.20 & 121.20 \\
Total production Cost & $€ m m / y r$ & 120.50 & 115.50 & 191.90 & 181.10 \\
Gas availability & $\mathrm{bcm} / \mathrm{yr}$ & 0.99 & 0.50 & 2.09 & 0.99 \\
cost per unit & $\mathrm{cent} / \mathrm{kWh}$ & 1.056 & 2.025 & 0.801 & 1.587 \\
VAT & $\mathrm{cent} / \mathrm{kWh}$ & 0.137 & 0.263 & 0.104 & 0.206 \\
Final cost per unit & cent/kWh & 1.193 & 2.288 & 0.905 & 1.793 \\
\hline
\end{tabular}

2.2879 cent $/ \mathrm{kWh}$, is yielded by the scenario where 1 FSRU unit store LNG for 10 weeks. Yet, this is $34.63 \%$ lower than the current per unit price of gas in Ireland [15]. It can be observed that the least economically favorable scenario is 'Storage for 10 weeks in 2 FSRUs'. It requires higher expenditure and yields relatively higher per unit price. The other scenarios can be implemented based on demand requirements.

Costs associated with the FSRU can be fixed or variable depending on whether the facility is secured under long-term or short-term contracts. FSRU costs can be applied on per day or per $\mathrm{m}^{3}$ basis. The charges are fixed if the contract is long-term. Otherwise, the regasification cost falls in the range $0.2-0.4 \$ / \mathrm{MMBtu}$ [16]. Hence, $14 \%$ variability is added to the regasification costs. Most of the European LNG capacity suggests that the only variable costs are the energy costs, which is $1 \%$ of the delivered gas [16]. The transportation cost comprises the daily charter component, fuel costs, port charges and insurance. The variable costs in transport are attributed to $40 \%$ [17]. Considering these variabilities, another economic estimate is produced (Table 5). The disadvantage in this format of economic estimate is the usage of fixed purchase price (purchase price in 2018) for LNG. In general, gas prices are affected by fluctuations in oil prices which is an economical substitute for natural gas power generators. They are driven also by supply and demand and can result in large price changes over a short period. Yet, fixed LNG price is used in the calculations, as the forecast by the US Energy Information Administration shows relatively steady LNG prices till 2050 [18].

Table 5: Fixed and variable cost estimation for the four scenarios.

\begin{tabular}{lcccc}
\hline & $\begin{array}{c}\text { Annual } \\
\text { Production } \\
\text { Cost (Fixed) } \\
(€ \mathbf{m m} / \mathbf{y r})\end{array}$ & $\begin{array}{c}\text { Per Unit Price } \\
(\text { Fixed) } \text { (cent/ } \\
\mathbf{k W h})\end{array}$ & $\begin{array}{c}\text { Annual } \\
\text { Production } \\
\text { Cost (Variable) } \\
(€ \mathbf{m m} / \mathbf{y r})\end{array}$ & $\begin{array}{c}\text { Per Unit Price } \\
(\text { Variable }) \\
(\text { cent/kWh })\end{array}$ \\
\hline 5 Weeks 1 FSRU & 120.50 & 1.1928 & 124.29 & 1.2430 \\
5 Weeks 2 FSRUs & 191.93 & 0.9050 & 199.96 & 0.9523 \\
10 Weeks 1 FSRU & 115.55 & 2.2879 & 117.45 & 2.3490 \\
10 Weeks 2 FSRUs & 181.08 & 1.7929 & 184.90 & 1.8490 \\
\hline
\end{tabular}




\section{CONCLUSIONS}

Based on the natural gas requirements of the end users, FSRU can be operated in continuous regasification mode, stand-by mode (where BOG is injected into the network), or as a storage facility. The simulation results demonstrate that it is technically feasible to operate FSRU as an LNG storage facility. The quality of LNG is not significantly affected after 10 weeks of storage and is compliant with the network specifications. The BOR increase from $0.129 \%$ to $0.14 \%$ per day of total volume is due to the increase in heat ingress into the storage tank and it is in line with the BOR specifications from FSRU manufacturers. The WI increased by $0.07 \%$ from the initial value and it remains within the specifications.

LNG storage in FSRU plays an important role in diversifying gas sources. It can be a reliable source to supply daily gas demand in small countries like Ireland can be operated as a substitute to pipeline imports and can serve in the integration of renewable resources by providing load-balancing services. Operating FSRU as a storage yields a significantly lower per unit price of gas. By operating FSRU as one of the gas sources (continuous regasification mode), gas can be supplied to consumers at a relatively lower price per unit. The per unit price of gas increased slightly (by 4\%) after considering the variability factors. Despite the dependency in oil price, establishing FSRU as storage is an economically attractive option in terms of diversification of gas sources and to ensure supply security.

\section{REFERENCES}

[1] International Gas Union. IGU 2018 world LNG report, September 2018. https://www. igu.org/sites/default/files/node-document-field_file/IGU_LNG_2018_0.pdf (accessed 18 February 2019).

[2] International Gas Union. IGU 2017 world LNG report, 2017. https://www.igu.org/ sites/default/files/103419-World_IGU_Report_no\%20crops.pdf (accessed 18 February 2019).

[3] International Gas Union. IGU 2015 world LNG report, 2015. https://www.igu.org/sites/ default/files/node-page-field_file/IGU-World\%20LNG\%20Report-2015\%20Edition. pdf (accessed 18 February 2019).

[4] Songhurst, B., The Outlook for Floating Storage and Regasification Units (FSRUs). Oxford Institute for Energy Studies, July 2017.

[5] Excelerate Energy. Excelerate energy FSRU fleet, 2018. http://excelerateenergy.com (accessed 18 February 2019).

[6] Wood, K., Gomes, I., Ho, B., Kerr, S., Cavanagh, S., Wood, D. \& Haywood, A., Guidebook to Gas Interchangeability and Gas Quality. BP/IGU, August 2011.

[7] Ervia and Gas Networks Ireland. A Look at the Irish Gas Market. Gas Networks Ireland, 2018.

[8] Brouwer, J., Mac Kinnon M.A. \& Samuelsen S., The role of natural gas and its infrastructure in mitigating greenhouse gas emissions, improving regional air quality, and renewable resource integration. Progress in Energy and Combustion Science, 64, pp. 62-92, January 2018. https://doi.org/10.1016/j.pecs.2017.10.002

[9] Sustainable Energy Authority of Ireland (SEAI). Energy statistics: Primary energy supply (mtoe)—natural gas (1990-2030), 2018. https://www.seai.ie/resources/publications/Commercial-Fuel-Cost-Comparison.pdf (accessed 18 February 2019).

[10] Ervia and Gas Networks Ireland. Transportation network monthly report, 2018. https://www.gasnetworks.ie/corporate/gas-regulation/transparency-and-publicat/2018reports/ (accessed 18 Febraury 2019). 
[11] Migliore, C., Tubilleja, C. \& Vesovic, V., Weathering prediction model for stored liquefied natural gas (LNG). Journal of Natural Gas Science and Engineering, 26, pp. 570-580, September 2015. https://doi.org/10.1016/j.jngse.2015.06.056

[12] Dimopoulos, G.G. \& Frangopoulos, C.A., A dynamic model for liquefied natural gas evaporation during marine transportation. International Journal of Thermodynamics, 11(3), pp. 123-131, September 2008.

[13] Dobrota, D., Lali' c, B. \& Komar, I., Problem of boil - off in LNG supply chain. Transactions on Maritime Science, 2(2), pp. 91-100, October 2013. https://doi. org/10.7225/toms.v02.n02.001

[14] European Commission. Technical information on projects of common interest, April 2018. https://ec.europa.eu/energy/sites/ener/files/technical_document_3rd_list_with_ subheadings.pdf (accessed 18 February 2019).

[15] SEAI. Commercial / industrial fuels: Comparison of energy costs, October 2018. https://www.seai.ie/resources/energy-data/ (accessed 18 February 2019).

[16] Trevor Sikorski. Energy Aspects. LNG regas costs: Fixed or variable? September 2017. https://www.energyaspects.com/publications/view/2017-09-06-natural-gas-naturalgas-global-lng-lng-regas-costs-fixed-or-variable (accessed 04 March 2019).

[17] Trevor Sikorski. Energy Aspects. LNG regas costs: Fixed or variable? April 2017. https://www.energyaspects.com/publications/view/2017-04-24-natural-gas-naturalgas-global-lng-insight-lng-transport-fixed-or-variable (accessed 04 March 2019).

[18] U.S. Energy Information Administration (EIA). Annual Energy Outlook 2019 with projections to 2050, January 2019. https://www.eia.gov/outlooks/aeo/pdf/aeo2019.pdf (accessed 04 March 2019). 